\title{
Spontaneous Internal Carotid Artery Dissection with Lower Cranial Nerve Palsy
}

\author{
N. Guy, D. Deffond, J. Gabrillargues, N. Carriere, G. Dordain, P. Clavelou
}

\begin{abstract}
Background: Typical presentation of spontaneous internal carotid artery (ICA) dissection is an ipsilateral pain in neck and face with Horner's syndrome and contralateral deficits. Although rare, lower cranial nerve palsy have been reported in association with an ipsilateral spontaneous ICA dissection. Case studies: We report three new cases of ICA dissection with lower cranial nerve palsies. Results: The first symtom to appear was headache in all three patients. Examination disclosed a Horner's syndrome in two cases (1 and 2), an isolated XIIth nerve palsy in two patients (case 1 and 3) and IX, X, and XIIth nerve palsies (case 2) revealing an ipsilateral carotid dissection, confirmed by MRI and angiography. In all cases, prognosis was good after a few weeks. Conclusions: These cases, analysed with those in the literature, led us to discuss two possible mechanisms: direct compression of cranial nerves by a subadventitial haematoma in the parapharyngeal space or ischemic palsy by compression of the ascending pharyngeal artery.
\end{abstract}

RÉSUMÉ: Dissection spontanée de l'artère carotide interne avec paralysie des derniers nerfs crâniens. Introduction: Le diagnostic de dissection de l'artère carotide interne (ACI) est le plus souvent évoqué devant l'association d'une douleur cervicale et d'un syndrome de Horner homolatéraux associés à un déficit moteur de l'hémicorps controlatéral. Plus rarement, une dissection carotidienne peut s'accompagner d'une paralysie homolatérale des derniers nerfs crâniens. Etude de cas: Nous décrivons 3 nouveaux cas de paralysie des derniers nerfs crâniens associée à une dissection de l'ACI. Résultats: Dans les trois cas une douleur céphalique fut le premier signe à apparaître, l'examen clinique mit en évidence un signe de Horner chez deux patients (1 et 2), une paralysie isolée du XIIe dans deux cas (1 et 3), et des IXe, Xe, XIIe nerfs crâniens dans un cas (2). Le diagnostic de dissection de l'ACI homolatérale fut confirmé par l'IRM et l'angiographie. L'évolution fut favorable en quelques semaines dans les trois cas. Conclusions: En analysant ces trois observations conjointement avec celles de la littérature, deux hypothèses physiopathologiques peuvent être proposées: un mécanisme compressif direct ou un mécanisme ischémique par compression de l'artère pharyngienne ascendante.

Can. J. Neurol. Sci. 2001; 28: 265-269

Spontaneous dissection of the internal carotid artery (ICA) was first described in 1959 by Anderson and Schechter. ${ }^{1}$ Since then, many reports have described the clinical features of this disorder, which are now well-recognised. The typical presentation of spontaneous ICA dissection is ipsilateral pain in the neck and face, accompanied by a Horner's syndrome. Contralateral focal cerebral lesions of ischemic origin are found. Lower cranial nerve palsy has rarely been reported in association with ipsilateral spontaneous ICA dissection. Infiltrating skull base tumours, trauma or inflammatory disease are more frequent causes of lower cranial nerve palsy. ${ }^{2}$ Three cases of spontaneous ICA dissection, with ipsilateral cranial nerve palsy but without central nervous system involvement, are described here.

\section{Case Reports}

\section{Case 1}

A 60-year-old, previously healthy, right-handed man, presented with posterior cephalalgia of sudden onset. Three days later, he experienced difficulty chewing and had persistent headache. On admission,

From the Fédération de Neurologie (NG, DD, NC, GD, PC) and Service de Neuroradiologie (JG), CHU de Clermont Ferrand, Clermont Ferrand, France. ReCeIVEd APRIL 17, 2000. ACCEPTED IN FINAL FORM MAY 15, 2001.

Reprint requests to: D. Deffond, Service de Neurologie B, CHU de Clermont Ferrand, BP69, 63003, Clermont-Ferrand CEDEX 1, France 


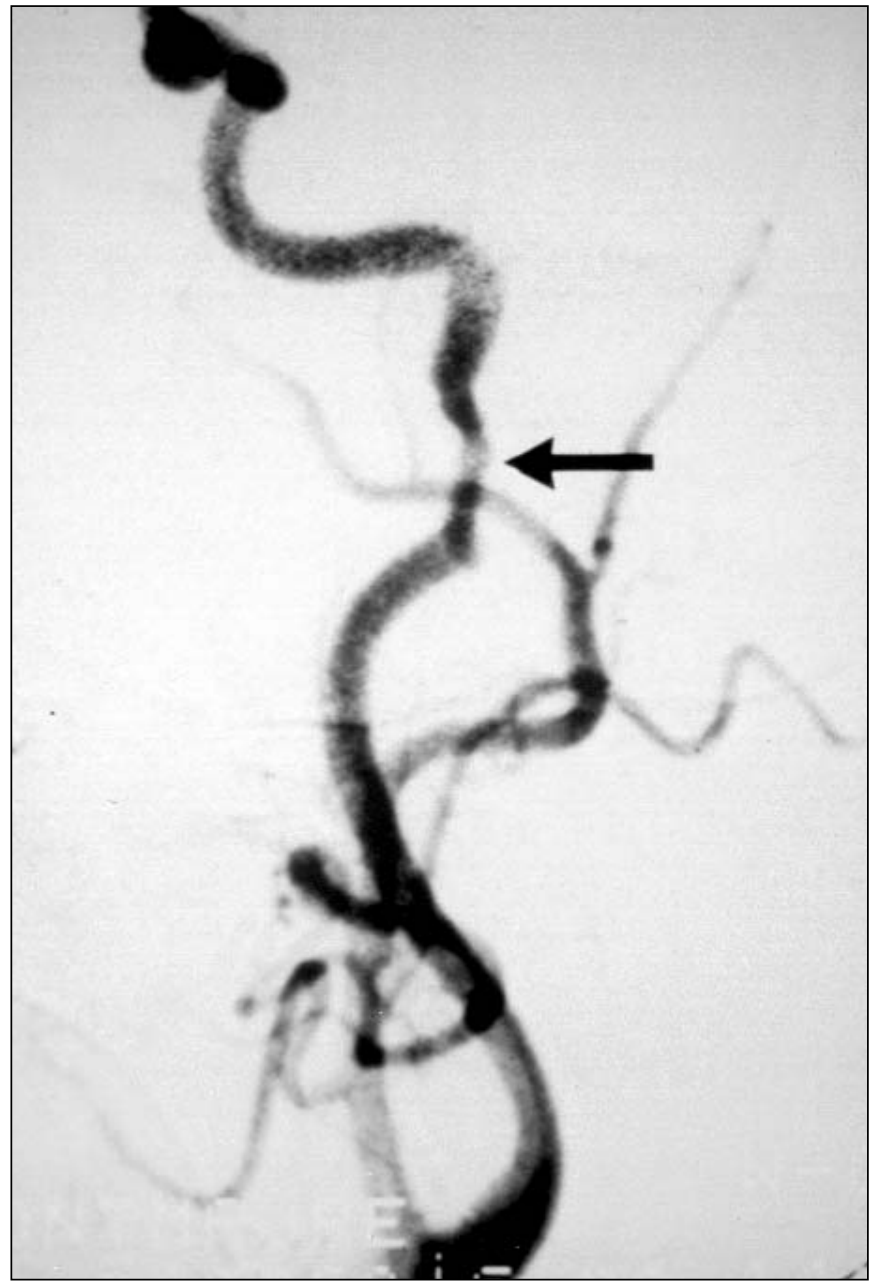

Figure 1: Case 1: Left carotid digital subtraction angiogram (lateral view): irregular stenosis of the internal carotid artery, likely due to focal dissection.

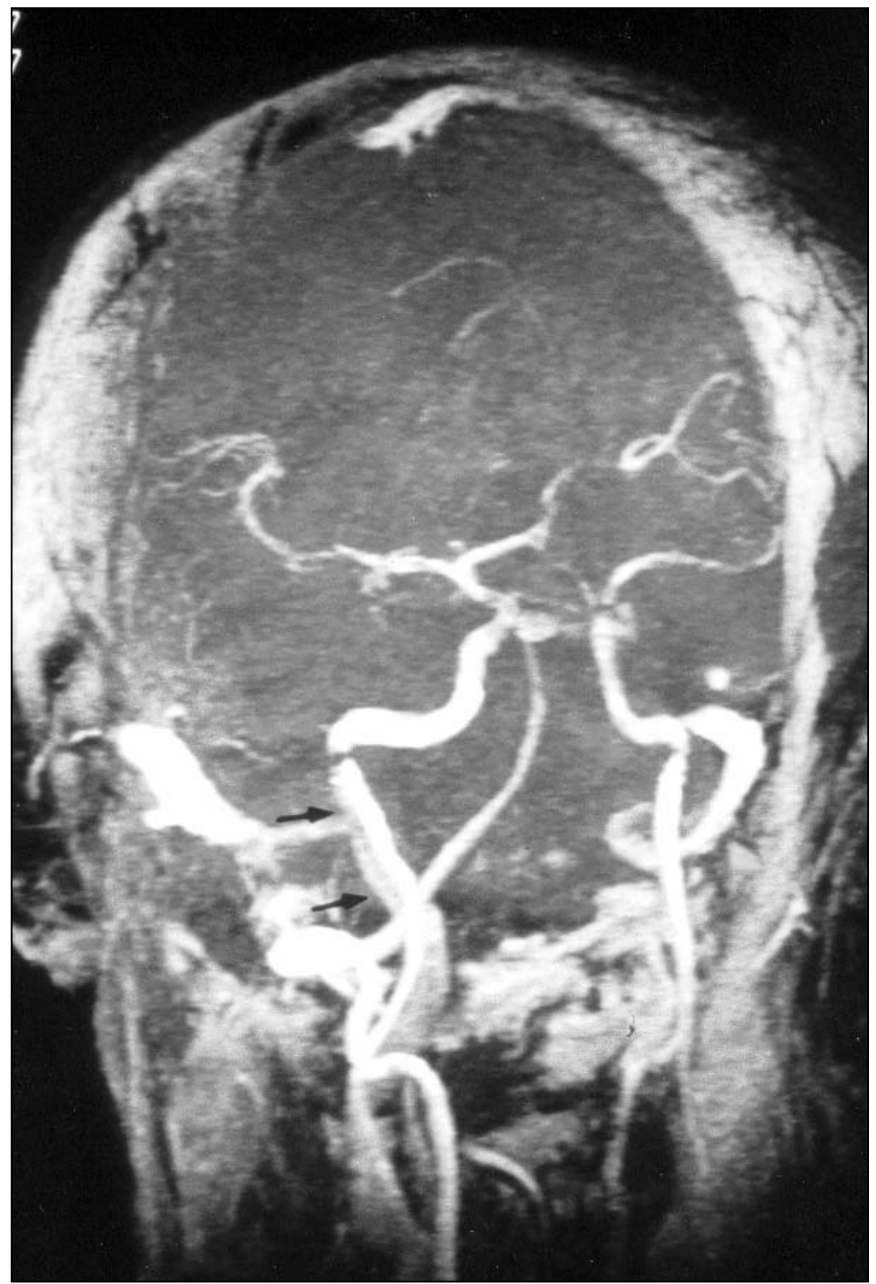

Figure 2: Case 2: MR angiography (TOF-MIP sequence, oblique view) intramural thrombus appearing as a hyperintense signal around the left carotid artery (arrows). examination disclosed a left hypoglossal nerve palsy, and a left Horner's syndrome. Cerebral CT scan was normal. A left carotid arteriogram revealed a slightly concentric narrowing of the ICA's prepetrous segment and confirmed the suspected diagnosis of ICA dissection (Figure 1). Heparin treatment was immediately started and after two weeks, aspirin was substituted. Two months later an MRI showed a crescentic hypersignal on T2 weighted images in the wall of the left carotid artery. Three months later, there was recovery of the left hypoglossal paresis but persistent Horner's syndrome.

\section{Case 2}

A 49-year-old, previously healthy, right-handed man, developed a sudden, severe left-sided headache with radiation to the left eye. Six days later, he noted difficulties in swallowing, chewing and numbness on the left side of the pharynx.

On admission, neurological examination showed paresis in the territory of the left IXth, Xth, and XIIth cranial nerves and a left Horner's syndrome. Cerebral CT scan was normal. A left carotid arteriogram revealed segmental stenosis starting $2 \mathrm{~cm}$ above the carotid bifurcation to the intrapetrous segment. An MRI performed three weeks after the onset of clinical signs showed a crescentic hyperintense signal on T2 weighted images in the wall of the left carotid artery that confirmed the presence of a dissection. Magnetic resonance angiography showed a hyperintense signal around the left carotid artery, typical of carotid dissection (Figure 2). Once the diagnosis had been made, heparin treatment was started, followed a week later by oral anticoagulant therapy for three months. Anticoagulant medication was stopped after repeat carotid angiogram and changed to $300 \mathrm{mg}$ of aspirin. At this time, neurological examination showed recovery of the cranial nerve palsies.

\section{Case 3}

A 51-year-old male was admitted to hospital for persisting diffuse headache and difficulties in swallowing. Several days previously, he had carried a heavy trunk on his right shoulder. On admission, neurological examination disclosed a right XIIth nerve palsy but was otherwise normal. Cerebral CT scan without contrast infusion was normal. Right carotid arteriogram showed localised stenosis of the ICA just before penetration into the carotid canal, strongly suggesting dissection in the prepetrous segment. At this point, oral anticoagulant therapy was started. Three months later, neurological examination and a repeat carotid arteriogram were normal. Oral anticoagulation was changed to $300 \mathrm{mg}$ of aspirin. 


\section{LITERATURE REVIEW}

These cases illustrate selective impairment of the lower cranial nerves by ICA dissection. Forty-six patients have previously been reported in the literature as having a similar syndrome. The association was first described by Kramer in $1969 .^{3}$

\section{Clinical findings}

Of the patients reported there were $39 \mathrm{men}^{3-30}$ and eight women, ${ }^{3,7,16,31-35}$ (sex ratio $=5: 1$ ). Gender was not identified for two patients. ${ }^{36}$ Two females suffered from fibromuscular dysplasia. $^{3,32}$ The mean age was 47.6 years (range 28 to 63 ). The left carotid artery was involved in 31 cases. ${ }^{3-19,31-36}$ For three patients, ${ }^{20-22}$ carotid dissection was bilateral but clinical signs were present only on the left. Ipsilateral Horner's syndrome was present in nineteen patients $(44 \%) .3,5-8,10,11,14,15,17,19,21,36$ For six patients, there were insufficient data. Pain was usually the initial manifestation and was experienced on the side of carotid dissection for $94 \%$ of patients. ${ }^{3-18,20-23,25-32,34-36}$ Although three patients had diffuse headache, ${ }^{7,32}$ others had focal unilateral headache, usually in the ipsilateral periorbital or temporal region. Six patients $(17 \%)^{6,9,10,20,32}$ had ispilateral neck pain alone. Cranial nerve palsy occurred within three to four days after the onset of pain. In 43 patients, an ipsilateral XIIth nerve palsy was reported $(88 \%)$. This cranial nerve was affected alone in 17 cases, ${ }^{4-9,13,15,18,23,27,29,31}$ in conjunction with the Xth nerve three times, ${ }^{5,7,30}$ with the XIth nerve once, ${ }^{10}$ with the IXth and Xth nerves ten times, $3,5,10,16,20,35,36$ with the IXth, Xth and XIth nerves in 11 cases $^{6,10,11,12,17,19,21,22,24,35}$ and with Vth, and VIIth nerve palsy in one patient. ${ }^{12}$ Symptoms of focal cerebral ischemia occured in seven cases $(17 \%)$ : one stroke ${ }^{5}$ with persistent contralateral hemiparesis, five transient ischemic attacks ${ }^{9,13,27,30,36}$ and one amaurosis fugax. ${ }^{7}$ Prognosis was good for 24 patients, with total recovery of cranial nerve paralysis. Six patients had persisting paresis, ${ }^{7,13,22,24,35}$ one had persisting headache $^{27}$ and another had no resolution of his Horner's syndrome. ${ }^{29}$ Ten patients had various degrees of improvement in their clinical signs. Prognosis was not listed for seven patients. Six patients $3,8,15,18,22,27$ underwent electromyography which showed fibrillation and denervation of the lingual muscles.

\section{Angiographic findings}

Forty-seven patients underwent angiographic examination. Thirty-seven patients $(78 \%)$ had stenosis. This was irregular for 31 patients $^{4-7,11-12,14,16-22,26,27,29,32-36}$ and string-shaped in six cases. 5,6,8,9,23,31 Pseudoaneurysm was present in 18 patients $^{3-}$ $6,7,13,20-22,24,26,27,29,32,35$ juxtaposed with narrowing for twelve. One patient had coiling associated with narrowing. ${ }^{34}$ A double lumen was found in two cases",12 and this was termed the "twisted ribbon sign". Two patients had tapering occlusion of the ICA. ${ }^{15,30}$ Localization of the dissection was known for 47 patients and involved the prepetrosal segment of the ICA in all cases. Dissection also involved the intrapetrosal segment of the ICA for four patients $(8 \%),{ }^{4,11,12}$ the cervical segment for eight patients $(16 \%), 4,5,7,15,25,30$ and cervical and intrapetrosal segments for one patient. $^{10}$

\section{MRI findings}

Twenty-nine patients underwent MRI after about three weeks (mean 23 days). ${ }^{4,7,10-12,14,17-20,22-25,27-28,30-31,34-35}$ Only one patient underwent MRI on the second day. ${ }^{4}$ In 14 patients, no information on timing was given.

In all cases, subacute wall haematoma appeared as crescentic high signal intensity on both T1 and T2-weighted images. On each section, the global diameter of the dissected carotid artery was increased compared to the contralateral carotid artery because of the presence of wall haematoma.

Magnetic resonance angiography was undertaken for four patients $^{18,24-25,31}$ and showed localised hyperintense broadening of the ICA corresponding to a wall haematoma. The second case study reported here showed intramural thrombus as a hyperintense signal alongside a dissected carotid artery about $2 \mathrm{~cm}$ above the carotid bifurcation leading to the intrapretrous segment.

\section{Discussion}

The frequency of lower cranial nerve palsy associated with ICA dissection may be underestimated because in some patients isolated cranial nerve palsy may be considered "idiopathic". Moreover, when hemispheric ischemia is present, the association could suggest "crossed paralysis" from a brain stem infarct. In general, carotid dissection is characterized by unilateral headache associated with ipsilateral Horner's syndrome and focal cerebral ischemic symptoms. ${ }^{21,36,37}$ The average age of the patients reported in the literature is 45 years and $70 \%$ of patients are between 35 and 50 years old. Men are more often involved than women (ratio: 3:2). ${ }^{37}$ These clinical features of carotid dissection without cranial nerve involvement are otherwise similar to those associated with cranial nerve palsy, except for the proportion of focal cerebral ischemic signs. Angiographic characteristics are different, however, particularly in the location of the dissection. In most cases of dissection with cranial nerve palsy the prepetrous section is involved. ${ }^{21}$

When cranial nerve palsy is associated with carotid dissection, the hypoglossal nerve is the most frequently affected. 4,30,37 In the majority of the cases reported, the association between XIIth nerve palsy, and the localization in the prepetrous segment of the ICA suggest a common, local mechanism in the cervical parapharyngeal space. The cervical parapharyngeal space contains the four lower cranial nerves, situated between the ICA medially and the jugular vein distally. The ascending pharyngeal artery, a branch of the external carotid artery, is also situated in the cervical parapharyngeal space in the vicinity of the ICA. The ascending pharyngeal artery usually divides into three branches: an anterior pharyngeal branch, a middle tympanic branch and a posterior neuromeningeal branch which itself divides into three branches. These branches are, rostrally to caudally, the jugular artery providing blood supply to the IXth, Xth, and XIth cranial nerves, the hypoglossal artery which ensures the vascularization of the XIIth cranial nerve, and the musculospinal branch which supplies the muscular ramus of the XIth nerve. ${ }^{38,39}$ The anatomy of the cervical parapharyngeal space allows two physiopathological explanations to be advanced for the phenomenon of lower cranial nerve palsy following spontaneous ICA dissection. Either a direct compressive mechanism acts on the adjacent cranial nerves or the nerves are affected by localised ischemia. Most authors 
suggest a compressive mechanism as an explanation for cranial nerve palsy. ${ }^{4-10,20,22,23,30,32}$ The IXth, Xth, XIth, and XIIth cranial nerves all lie close to the internal carotid artery and may be involved in the expanded wall haematoma that can nearly triple the ICA diameter. ${ }^{5,10}$ Findings from MRI, MR angiography and the known anatomy of the cervical parapharyngeal space support this hypothesis. Disruption of perivascular sympathetic fibers by a wall haematoma could also explain Horner's syndrome. The XIIth nerve is the closest to the ICA, which could explain why it is the most frequently involved. The good prognosis also suggests a compressive mechanism, as spontaneous resolution of nerve palsy may occur as the dissecting aneurysm decreases in size. ${ }^{20}$ Furthermore, the average delay of four days between the onset of pain and cranial nerve palsy supports this hypothesis of local compression. Sturzenegger et al, ${ }^{4}$ suggest that dissections accompanied by lower cranial nerve palsy are more often subadventitial than subintimal because there is a higher prevalence of aneurysm and a lower prevalence of ischemic cerebral events in these cases. Aneurysm formation leads to compression of the adjacent structures. De Brouker et $\mathrm{al}^{35}$ report a 55-year-old man, with a left IX, X, XI, and XII nerve paresis due to prepetrous ICA dissection. This patient underwent carotid angiogram and MRI which showed subadventitial dissection. Selective study of the ascending pharyngeal artery was normal. Scotti et $\mathrm{al}^{40}$ report a case of XIIth nerve paresis due to stretching and compression between a loop of the internal carotid artery and the sternocleidomastoid branch of the occipital artery, discovered during surgical exploration. The hypoglossal nerve was very thin at the point where it was trapped between the two vessels. This surgical finding may suggest that a similar mechanism occurs in dissection.

A few authors recognize ischemia as a possible mechanism. 4,6,7,10,29,41 This possibility is supported by the position of the ascending pharyngeal artery in the parapharyngeal space, close to the ICA. An embolic mechanism is improbable because the ascending pharyngeal artery is a branch of the external carotid artery and dissection rarely involves the carotid bifurcation (except if there is anatomical variation). ${ }^{8,22}$ An expanded wall haematoma of the ICA could, however, compress the ascending pharyngeal artery. ${ }^{6,7,10}$ Rare accidents during embolization of the ascending pharyngeal artery have been reported. Manifestations are varied: ear pain; XIIth nerve palsy; X, XI, and XIIth nerves palsy or IX, X, XI and XIIth nerves palsy. ${ }^{38}$ Furthermore, XIIth nerve palsy only occurs rarely following carotid artery surgery, particularly endarteriectomy (4.6\% to $13.4 \%$ depending on series), perhaps arguing against a compressive mechanism. ${ }^{42,43}$ An ischemic hypothesis, however, does not clearly explain the delay between the first signs of dissection and involvement of the cranial nerves.

A third explanation has been evoked by certain authors: ${ }^{29,41}$ congenital malformations of the arterial wall are often associated with the persistence in adult life of fetal vessels, as such the primitive hypoglossal artery which leaves the ICA close to the base of the skull. Occlusion of this vessel may cause nerve infarction.

In summary, the association between cranial nerve palsy and dissection of the cervical ICA may be a result of a compressive mechanism, suggested by its anatomical relationships, the characteristics of the dissection, the delay of cranial nerve paralysis and the good prognosis. MRI, magnetic resonance angiography and angiography (when selective study of the external carotid is undertaken) could help to clarify this possibility by showing the anatomical relationship between the wall haematoma, the cranial nerves and the ascending pharyngeal artery in the parapharyngeal space..$^{6,7,10,11,23}$

\section{REFERENCES}

1. Anderson RM, Schechter MM. A case of spontaneous dissecting aneurysm of the internal carotid artery. J Neurol Neurosurg Psychiatry 1959; 22: 195-201.

2. Thommasi-Davenas C, Vighetto A, Confavreux C, Aimard G. Causes des paralysies du nerf grand hypoglosse. Presse Med 1989; 864-868.

3. Kramer W. Hyperplasie fibromusculaire et anévrysme extracranien de la carotide interne avec syndrome parapharyngien typique. Rev Neurol 1969; 4: 239-244.

4. Sturzenegger M, Huber P. Cranial nerve palsy in spontaneous carotid artery dissection. J Neurol Neurosurg Psychiatry 1993; 56: 1191-1199.

5. Hommel M, Pollack P, Gaio JM, et al. Paralysies du nerf grand hypoglosse par deux anévrysmes et un anévrysme disséquant de la carotide interne. Rev Neurol 1984; 6-7: 415-421.

6. Bradac GB, Kaernbach A, Bolk-Weichedel D, Finck GA. Spontaneous dissecting aneurysm of cervical cerebral artery. Neuroradiology 1981; 21: 149-154.

7. Bradac GB, Riva A, Stura G, Doriguzz C. Dissection spontanée de la carotide interne avec paralysie du XII. J Neuroradiol 1989; 16: 197-202.

8. Vighetto A, Lisovoski F, Revol A, Trillet M, Aimard G. Internal carotid artery dissection and ipsilateral hypoglossal nerve palsy. J Neurol Neurosurg Psychiatry 1990; 53: 530-531.

9. Goodman JM, William LZ, Cooper DF. Hemilingual paralysis caused by spontaneous carotid artery dissection. Arch Neurol 1983; 40: 653-654.

10. Dal Pozzo G, Mascalchi M, Fonda C, et al. Lower cranial nerve palsy due to dissection of the internal carotid artery: CT and MR imaging. J Comput Assist Tomogr 1989; 13: 989-995.

11. Goldberg HI, Grossman RI, Gomori JM, et al. Cervical internal carotid artery dissecting hemorrhage: diagnosis using MR. Radiology 1986; 158: 157-161.

12. Panisset M, Eidelman BH. Multiple cranial neuropathy as a feature of internal carotid artery dissection. Stroke 1990; 21: 141-147.

13. Gros G,Vlahovitch B, Labauge R, et al. Les anévrysmes extracraniens de la carotide interne. Neurochirurgie 1970; 5: 367-382.

14. Taillibert S, Bazin B, Pierrot-Deseilligny C. Dysgueusia resulting from internal carotid dissection. A limited glossopharyngeal palsy. J Neurol Neurosurg Psychiatry 1998; 64: 691-692.

15. Vanneste JAL, Davies G. Spontaneous dissection of the cervical internal carotid artery. Clin Neurol Neurosurg 1984; 86-4: 307314.

16. Koch J, Klotz JM, Kahle G, Langohr HD. Unilateral lower cranial nerve palsies caused by extracranial carotid artery dissection. Fortschr Neurol Psychiat 1994; 62: 46-49.

17. Klossek JM, Vandenmarq P. Unilateral lower cranial nerve palsies due to spontaneous internal carotid artery dissection. Ann Otol Rhinol Laryngol 1994;103: 413-415.

18. Auzou P, Hannequin D, Patrux B, et al. Atteinte du grand hypoglosse révélant une dissection de l'artère carotide interne. Ann Otolaryngol Chir Cervicofac 1996; 113: 45-47.

19. Schmidt F, Dihne M, Steinbach J, Burhing U, Kuker W. Raeder and Collet-Sicard syndrome. Acute paresis of cranial nerves symptomatic of a dissection of internal carotid artery. Nervenarzt 2000; 71: 502-505.

20. Waespe W, Niesper J, Imhof HG, Valavanis A. Lower cranial nerve palsy due to internal carotid dissection. Stroke 1988; 19: 15611564 .

21. Mokri B, Sundt TM, Houser OW, Piepgras DG. Spontaneous dissection of the cervical internal carotid artery. Ann Neurol 1986; 19: 126-138. 
22. Rees JH, Valentine AR, Llewelyn JG. Spontaneous bilateral carotid and vertebral artery dissection presenting as a Collet-Sicard syndrome. Brit J Radiol 1997; 70: 856-858.

23. Lieshke GJ, Davis S, Tress BM, Ebeling P. Spontaneous internal carotid artery dissection presenting as hypoglossal nerve palsy. Stroke 1988; 19: 1151-1155.

24. Ruiz J, Varona L, Martin-Gomez JI, et al. Diseccion espontannea de la arteria carotida interna como causa de paralisis de pares craneales bulbares. Neurologia 1995; 10: 391-393.

25. Nusbaum AO, Som PM, Dubois P, Silvers A. Isolated vagal nerve palsy associated with a dissection of the extracranial internal carotid artery. Am J Neuroradiol 1998; 19: 1845-1847.

26. Wannebroucq J, Petyt L, Cassim JF, Rondepierre PH, Pruvo JP. Dissection de l'artère carotide interne révélée par une paralysie isolée des IX, X, XI nerfs craniens. Rev Im Med 1993; 5: 495-497.

27. Zipp F, Herdt P, Goetz GF, et al. Isolierte einseitige hypoglossusparese bei karotisdissektion. Nervenarzt 1993;64: 535-538.

28. Moussouttas M, Tuhrim S. Spontaneous internal carotid artery dissection with isolated vagus nerve deficit. Neurology 1998; 51: 317-318.

29. Anzola GP, Gualandi GF, Orlandini A, Scipione V. Lower cranial nerve palsy produced by internal carotid artery dilatation. Report of two cases. Ital J Neurol Sci 1987; 8: 375-379.

30. Hess D, Sethi KD, Nichols FT. Carotid dissection: a new false localising sign. J Neurol Neurosurg Psychiatry 1990; 53: 804-805.

31. Boukobza M. Internal carotid artery dissection causes hypoglossal nerve palsy: CT, MRI, and angiographic findings. J Neuroimag 1998; 8: 244-246.

32. Serre I, Delattre JY, Poisson M. Dissection carotidienne et paralysie homolatérale du XII. Ann Med Interne (Paris) 1993; 7: 500-502.
33. Davies L. A vagal palsy due to dissecting aneurysm of the carotid artery. Med J Aust 1987; 147: 352-353.

34. Heckmann JG, Tomandl B, Stefan H, Neundörfer B. Collet-Sicard syndrome due to coiling and dissection of internal carotid artery. Cerebrovasc Dis 2000; 10: 487-488.

35. De Brouker T, Lacombe H, Danziger N, Baril P, Sangla S. Paralysie unilatérale des derniers nerfs craniens par lésion de l'artère carotide interne. Rev Neurol 1994; 150: 850-853.

36. Gauthier G, Rohr J, Wildi E, Megret M. L'hématome disséquant spontané de l'artère carotide interne. Arch Suisses Neurol Psychiatr 1985; 136: 53-74.

37. Hart RG, Easton DJ. Dissections of cervical and cerebral arteries. Barnett HJM (ed). Cerebrovascular Disease. Neurol Clin 1983; 1: 155-182.

38. Lasjaunias P, Doyon D. L'artère pharyngienne ascendante dans la vascularisation des dernières paires craniennes (IX, X,XI, XII). J Neuroradiology 1978; 5: 287-301.

39. Lapresle J, Lasjaunias P. Cranial nerve ischaemic arterial syndromes - A review. Brain 1986; 109: 207-215.

40. Scotti G, Melancon D, Olivier A. Hypoglossal paralysis due to compression by a tortuous internal carotid artery in the neck. Neuroradiology 1978; 14: 263-265.

41. Havelius U, Hindfelt B, Brismar J, Cronqvist S. Carotid fibromuscular dysplasia and paresis of lower cranial nerves (ColletSicard syndrome). Case report. J Neurosurg 1982; 56: 850-853.

42. Theodotou B, Mahaley MS. Injury of the peripheral cranial nerves during carotid endarterectomy. Stroke 1985; 16: 894-895.

43. Maniglia AJ, Peter-Han D. Cranial nerve injuries following carotid endarterectomy: an analysis of 336 procedures. Head Neck 1991; 13(2): 121-124. 